\title{
LOTERIJEN IN SURINAME
}

DOOR

G. PH. ZAAL

Tenzij ergens, waar men het niet aanstonds verwachten zou, verscholen, bevat de Encyclopaedie van Neder1 a n d s h W e s t-I n d i ë geen artikel over loterijen en hazardspelen, voor Suriname en Curaçao toch wel van belang.

Het volgende moge ter oriënteering dienen.

Op hun, den 25sten November 1937 gehouden, openbare vergadering behandelden de Koloniale Staten van Suriname o.m. eene ontwerp-landsverordening houdende bepalingen betreffende loterijen.

De daarbij gehouden algemeene beschouwingen leverden voor een aanzienlijk deel het materiaal voor de samenstelling van dit opstel.

Het ware wenschelijk geweest in het intitulé van het ontwerp te gewagen van „nieuwe bepalingen”, omdat, voor zooveel is kunnen worden nagegaan, reeds ongeveer twee eeuwen geleden in Suriname de eerste stappen zijn gedaan om loterijen onder overheidstoezicht te stellen.

In de "Geschiedenis der belastingen in de Kolonie Suriname" van A. G. van Wieringen, verschenen in 1912 en gedrukt ter Algemeene Landsdrukkerij te 's-Gravenhage, staat vermeld, dat bij resolutie van Gouverneur en Raden van Politie en Crimineele Justitie van 26 Februari 1750 voorgeschreven werd, dat voor het houden van loterijen „eene permissie" noodig was. Die maatregel was genomen na overweging, dat het houden van loterijen veel nadeel toebracht aan het destijds bestaande kantoor der venduen. Er moeten op die wijze soms geheele inboedels aan den man zijn gebracht, waardoor de betaling van vendurechten kan worden ontgaan.

In December 1758 werd eene heffing van $1 \%$ op de loterijen 
vastgesteld, welk recht echter gedurende geruimen tijd òf zelden of in het geheel niet werd geheven. De opbrengst ervan is althans altijd gering geweest; terwijl het doel ook wel bereikt werd door het verbinden van het houden van loterijen aan eene overheidsvergunning. Het was namelijk niet mogelijk gebleken altijd vooraf behoorlijk vast te stellen, of men met eene eigenlijke loterij had te doen.

Bij Publicatie van den Gouverneur-Generaal Cantz'laar van 26 Augustus 1828 (G.B. No. 9) werd de zaak opnieuw geregeld.

De considerans dier Publicatie luidt:

„dat het tot heden binnen de Kolonie gebruikelijk is geweest „om goederen te verloten met voorkennis en toestemming van het "gewezen Officie-Fiskaal, waarvan aan den Lande niet meer dan „het zegelrecht werd voldaan;

„dat het verloten van goederen moet gelijk gesteld worden met „eene publieke wijze van overgang van eigendom;

„dat bij publieken verkoop van goederen onderscheidene rech„ten ten behoeve van den Lande moeten worden voldaan;

„dat ook zonder deze redenen voor het belang van de Koloniale „kas er nog andere in het belang van het algemeen bestaan welke „niet minder in aanmerking moeten komen en wel voornamelijk „dat de verloting van goederen onder een meer bepaald toezicht „behoort te worden gesteld, tot voorkoming van alle ongeregeld„heden, die daaromtrent zouden kunnen plaats hebben."

Deze overwegingen spreken ons van de goede behartiging van 's Lands belang, welke ook in den ouden tijd voorkwam, en doen blijken van een juist inzicht in deze angelegenheid, dat tevens gelegenheid gaf om de inkomsten der koloniale kas te verhoogen.

In denzelfden geest is Curaçao gevolgd onder het Bestuur van den vorigen gouverneur Van Slobbe. Het Curaçaosche Bestuur heeft de stichting weten te bevorderen van een loterijbond van permanenten aard. Dag van oprichting van dien bond, waaraan de naam „Fortuna” is gegeven, was 7 Juli 1932. De nettoopbrengst der door dien bond georganiseerde loterijen is uitsluitend bestemd tot stijving der kassen van vereenigingen en stichtingen, die een liefdadig doel of de bevordering van wetenschap, kunst of een ander algemeen belang nastreven. In 1936 profiteerden niet minder dan 27 vereenigingen en stichtingen van die loterijen. Verder worden o.a. aan een directeur en den administrateur salarissen toegekend onderscheidenlijken tot bedragen „naar reden van" $f$ 3000.- en $f$ 13.200.-

De Curaçaosche loterij deed daarenboven over 1936 eene som 
van $f$ 98175.- - in 's Lands kas vloeien (de raming bedroeg $f 75.000$ Voor 1937 en 1938 is de opbrengst van dit middel geraamd op $f$ 95.000. (Men zie de „Toelichting van de Raming der middelen en inkomsten van Curaçao voor het dienstjaar 1938", behoorende bij de desbetreffende ontwerp-begrooting).

Dat hierdoor Curaçao niet slechts rechtstreeks voordeel voor hare algemeene kas kon behalen, maar daardoor tevens het uittrekken of verhoogen van credieten op de begrooting ten behoeve van de genoemde doeleinden tot een uitzondering zal gaan behooren, zoo niet geheel zal worden voorkomen, schijnt heel duidelijk.

Gelet op den omvang van den omzet der loterijen van „Fortuna" - „om de drie weken" konden 10500 loten à $f 11$. - worden verkocht, alzoo „om de drie weken" een omzet van $\pm f 11500$ d.i. $f$ 1.963.500.- 's jaars - en daartegenover gelet op den ongunstiggen economischen toestand in Suriname, zouden in dit laatste gewest zulke loterijen op den duur weinig kans van slagen hebben. Als volksloterijen op korten trekkingstermijn zouden ze ook niet geheel voldoen.

Niettemin zou op het het stuk van loterijen aanbeveling verdienen in Suriname te handelen in den geest van het Curaçaosche Gouvernement. In het Voorloopig Verslag der Commissie van Rapporteurs uit de Koloniale Staten van 25 Februari 1936 werd zulks aan het Bestuur ter overweging aanbevolen en als posten, waarmede de Surinaamsche begrooting geleidelijk zou kunnen worden ontlast, werden aangegeven, die voor werkeloosheid, armenzorg en voor ouden en gebrekkigen.

Blijkens de Surinaamsche begrooting voor 1936 hebben deze posten over 1934 tezamen het bedrag van $f$ 262.813.- - beloopen. Dergelijke credieten worden niet aangetroffen op de begrootingen van Curaçao. $\mathrm{Zal}$ het bij de aldaar in industrie en bedrijf bestaande welvaart wel zelden noodig voorkomen ten laste van 's Lands kas uitgaven te brengen ten behoeve van noodlijdenden, - in Suriname is dit gansch anders.

In de op het genoemde verslag gevolgde Memorie van Antwoord van 24 Juli 1936 is evenwel door het Surinaamsch Bestuur op het denkbeeld der Staten niet ingegaan.

De bij de Publicatie van 1828 gegeven „voorschriften hoedanig te handelen bij het verloten van goederen" zijn gedeeltelijk nog van kracht en behelzen de algemeene bepalingen betreffende verlotingen in Suriname. $\mathrm{Zij}$, die zich daaraan niet houden, kunnen 
gestraft worden ingevolge artikel 471 van het Wetboek van Strafrecht voor Suriname.

De vervallen bepalingen dier Publicatie betreffen de uit verlotingen voor den Fiscus te behalen voordeelen. $\mathrm{Zij}$ zijn vervangen door de regeling, vervat in de op 1 Januari 1934 inwerking getreden Verordening van 27 December 1933 op de Loterijbelasting (G.B. No. 103).

De in den aanhef dezes vermelde ontwerp-landsverordening heeft o.a. ten doel de vervanging van de nog van kracht zijnde voorschriften, t.w. de algemeene bepalingen der aangehaalde Publicatie en van art. 471 van het Wetboek van Strafrecht. Verder is in dat ontwerp opgenomen een tweetal nieuwe bepalingen, welke betrekking hebben op buitenlandsche loterijen en eene omschrijving van het begrip „loterij” geven, zooals wordt gevonden in de Nederlandsche loterijwet 1905.

Aan de indiening door Gouverneur Kielstra, op 12 Maart 1935, bij het Staten-College van de meerbedoelde ontwerp-landsverordening was voorafgegaan de aanbieding door Gouverneur Rutgers, op 25 April 1931, van een ontwerp-verordening tot wijziging en aanvulling van het Wetboek van Strafrecht voor de Kolonie Suriname met betrekking tot het bepaalde omtrent loterijen.

Vraagt men waarom het ontwerp-Rutgers niet is tot stand gekomen en waarin het verschil tusschen dat ontwerp en het ontwerp-Kielstra gelegen is, dan blijkt bij onderzoek het volgende:

Naar het ontwerp-Rutgers zou men van het Bestuur vergunning kunnen bekomen, niet alleen voor het houden van- en het deelnemen aan binnenlandsche loterijen, welke liefdadige doeleinden of de bevordering van algemeene belangen nastreven, doch ook de deelneming aan buitenlandsche loterijen van soortgelijken aard werd mogelijk gemaakt. Door evenals die aan binnenlandsche loterijen, de deelneming aan buitenlandsche loterijen afhankelijk te stellen van een van overheidswege daartoe verleende vergunning zouden de buitenlandsche loterijen kunnen worden beperkt, desnoodig, worden geweerd. Daarnevens wenschte gouverneur Rutgers de in den handel voorkomende inventies, waarmee koopers worden gelokt, voor zooveel deze niet kunnen worden gerangschikt onder loterijen, waarvoor vergunning zou kunnen worden verleend, te verbieden.

Deze voorstellen konden vrijwel bij geen der toenmalige leden der Koloniale Staten algeheele instemming verwerven. Men wees erop, dat in Suriname niet was gebleken van eenige moeilijkheid of buitensporigheid als gevolg van het deelnemen aan eenige bui- 
ten de kolonie aangelegde of gehouden loterij. Evenmin waren, voor zooveel bekend, klachten voorgekomen over de hier te lande door den handel aangeboden wordende gelegenheden om, na voldoening aan zekere voorwaarden, mede te dingen naar prijzen of premiën in geld of goed. Door het College werd verder onder des Bestuurs aandacht gebracht, dat, in tegenstelling zoo niet met alle, dan toch met vele landen, er in Suriname, ondanks het desbetreffend sterk en herhaaldelijk uitgesproken verlangen van de bevolking, niet bestaat een onder overheidstoezicht staande permanente loterij.

Wanneer een dergelijke loterij hier zou bestaan en er mitsdien aan een in breede lagen onder de bevolking levend verlangen zou worden tegemoetgekomen, zou, naar de algemeen gedeelde overtuiging, de animo om aan buitenlandsche loterijen mede te doen, bij het daaromtrent hier bestaande gemis aan contrôle, zoo niet geheel, dan toch aanmerkelijk luwen. Bovendien viel rekening te houden met den gunstigen invloed, die men verwachtte van het bestaan eener volksloterij bij de bestrijding van het Chineesch hazardspel „Piauw”. Voorts leveren de beduidende voordeelen, welke in het algemeen loterijen voor 's Lands kas zouden kunnen afwerpen, mede een goede reden op om aan loterijen geen belemmeringen in den weg te leggen.

Deze overwegingen leidden tot de indertijd algemeen door het Staten-College gedeelde slotsom, dat eerst wanneer eene onder contrôle der overheid staande permanente loterij hier kon worden gehouden, er gegronde redenen zouden kunnen ontstaan om het deelnemen aan buitenlandsche loterijen tegen te gaan, al zou het dan slechts zijn, om het aan deze loterijen te besteden geld zooveel mogelijk aan de eigen gemeenschap ten goede te doen komen. (Voorloopig Verslag der Commissie van rapporteurs over het genoemde Ontwerp dd. 23 November 1931).

Het ontwerp-Kielstra wil, in afwijking van dat van Gouverneur Rutgers, buitenlandsche loterijen geheel stopzetten en weren. Hierin bestaat hoofdzakelijk het verschil tusschen de beide ontwerpen.

De stand van zaken op het gebied van loterijen is sedert 1931 dezelfde als daarvóór. De enkele uitzonderingen daarop maakten de klachten uit, welke in 1933 en 1934 zijn vernomen van de „Stephan's kwartjesloterij”.

Tot goed begrip van zaken is het gewenscht over deze loterij het een en ander mede te deelen.

Tot het houden hiervan was aanvankelijk door gouverneur 
Rutgers in Maart 1932 vergunning gegeven aan M. H. Stephan. Deze vergunning betrof eene zuivere geldloterij met korten trekkingstermijn.

Door het gedurende een aan dien gouverneur verleend verlof opgetreden tusschenbestuur van Mr. Dr. Van Haaren, werden eind September 1933 voor die loterij zoodanige wijzigingen en aanvullingen goedgekeurd, dat zij geheel ontaardde in het als een volkskanker aangeduide „Piauw”.

De tegen den gewijzigden vorm dier loterij uit de Koloniale Staten en de bevolking gerezen, bij herhaling tot uiting gekomen klachten, voornamelijk de principieele klacht van het oud-Statenlid A. A. Dragten, hadden tot gevolg de veroordeeling in Mei 1934 van den voornoemden loterijhouder bij vonnis van het Hof van Justitie wegens het opzettelijk geven van gelegenheid tot hazardspel en als bedrijf uitoefenen van dat spel.

Het Gouvernement bleef daarbij buiten schot, omdat in de beschikking van den Waarnemenden Gouverneur van 30 September 1933, waarbij de Stephan's loterij werd toegelaten, eene clausule was opgenomen luidende:

„Te bepalen, dat het Bestuur geen enkel risico op zich neemt, „indien Politie of Justitie deze loterij als hazardspel, althans als „een zoodanig spel waarvoor het Bestuur (Gouverneur) geen ver„gunning onder de benaming van loterij of hoe anders ook zou mo„gen geven, beschouwt en behandelt, of welk ander risico ook, als "gevolg of in verband met deze vergunning en de verleening daarvan".

Reeds van den aanvang af scheen dus te zijn gevoeld dat de Stephan's loterij hazardspel kon zijn. Het bestaan van sterke twijfel bij het toenmalig interregnum omtrent den aard dier loterij was in elk geval niet te ontkennen en kwam door de aangehaalde bepaling duidelijk aan het licht. De vraag of het onder deze omstandigheid gerechtvaardigd of verstandig was de loterij toe te staan, kan hier buiten beschouwing blijven. Na het voormelde vonnis van het Hof van Justitie moest de aan den voornoemden loterijhouder verleende vergunning worden ingetrokken, hetgeen dan ook door Gouverneur Kielstra ten spoedigste (binnen weinige uren) werd gedaan.

Op het ontwerp-Rutgers, dat in de Koloniale Staten nog niet in openbare behandeling was gekomen, had het College intusschen geen eindbeslissing kunnen nemen. Gewacht werd op de beantwoording van het over dat ontwerp uitgebracht Voorloopig Verslag, voor welke taak Gouverneur Kielstra zich bij de aan- 
vaarding van het Bestuur over Suriname geplaatst zag. Zich in zijne Memorie van Antwoord van 15 Januari 1934 - enkele maanden dus vóór het voormelde vonnis was uitgesproken - van die taak kwijtende, werd door den Gouverneur met een beroep op de toen sterk nog gespeeld wordende "Stephan's kwartjes loterij”, bij de Staten aangedrongen op de goedkeuring van het ontwerp van zijn voorganger.

Woordelijk staat in die Memorie te lezen:

„Deze loterij heeft nu bijna twee jaren gewerkt en heeft inmiddels hare bestaansmogelijkheid bewezen.

„Daarmede is bereikt dat inderdaad is voorzien in iets, dat de „bevolking niet schijnt te kunnen missen - van eene „behoefte”, „die hieraan bestaat zou ondergeteekende niet met het Voorloopig „Verslag kunnen spreken - en dat de nu eenmaal blijkbaar niet te „vermijden loterij met alles wat daarop betrekking heeft staat „onder streng toezicht van de Overheid. Als voordeel van het „systeem kan voorts nog gelden, dat de aan deze loterij bestede "gelden praktisch genomen in het land blijven en bijna geheel der „Surinaamsche gemeenschap ten goede komen; terwijl tegelijker"tijd 's Lands kas daarbij in niet geringe mate baat vindt, en ten "slotte dat het piauwspel ontegenzeggelijk is afgenomen in om"vang."

„Nu door een ander - aldus de gouverneur verder + de in het „Voorloopig Verslag tot uiting gekomen wenschen ten deze fei„telijk voor een goed doel bevredigd kunnen worden geacht, ver„trouwt ondergeteekende dat, bij nadere beschouwing, het onder„havige voorstel alsnog de instemming der leden zal verkrijgen, „zooals hij trouwens meent, dat te beluisteren valt uit het 5 de lid „van het Voorloopig Verslag".

$\mathrm{Al}$ deed het beroep op de Stephan's loterij vreemd aan, met het oog op de tegen die loterij zoowel door de Koloniale Staten als door de Pers bij herhaling gedane waarschuwingen en ingebrachte klachten, uit het citaat blijkt van des Bestuurs adhaesie, geschonken aan de motieven, door het College aangevoerd voor het in het leven roepen eener goede Volksloterij. Men kwam door dat beroep eveneens onder den indruk dat de Gouverneur zich vereenigd had met den wensch der Staten om in afwachting van de totstandkoming eener zoodanige loterij de deelneming aan buitenlandsche loterijen niet dadelijk te beletten.

Het uit de Memorie van Antwoord aangehaalde is wijders een onweerlegbaar bewijs ervan, dat de van een zoodanige loterij gekoesterde verwachtingen bevredigd zullen kunnen worden. 
Dat het College nogtans voor de Stephan's loterij geen bewondering had, kwam voor de zooveelste maal aan het licht bij de openbare behandeling op 31 Mei 1934 van het ontwerp-Rutgers (men zie het verslag dezer zitting; Handelingen Koloniale Staten 1934-1935, Vellen $4 \mathrm{t} / \mathrm{m}$ 6). Daarbij bleek men van gevoelen te zijn, dat, waar het gedane beroep niet kon opgaan, het ontwerp ò moest worden verworpen, òf door het Bestuur moest worden teruggenomen, dan wel de behandeling daarvan moest worden opgeschort, totdat inderdaad zou kunnen worden gewezen op het bestaan eener goede Volksloterij. Dit laatste werd ten slotte door het College in groote meerderheid goedgekeurd.

De zaak bevond zich in dezen toestand, toen gouverneur Kielstra zijn ontwerp indiende en tegelijkertijd introk het ontwerp van zijn voorganger.

De toelichting, waarvan de Gouverneur zijn ontwerp-verordening deed vergezeld gaan, was niet geheel in overeenstemming met de voorafgegane gebeurtenissen. Evenmin waren volkomen juist te achten de in die toelichting voorkomende aan die gebeurtenissen vastgeknoopte beschouwingen. Zoo werd in het vorenmedegedeelde besluit van het College door den Gouverneur ineens gezien ,een streven tot het uitoefenen van invloed op eene be„slissing welke krachtens de bestaande wetgeving tot de be„voegdheid van den Gouverneur behoort en voor het nemen waar"van deze dus tenvolle de verantwoordelijkheid draagt".

De Staten mochten deze beschuldiging niet aannemen en deden daarvan blijken in het over het ontwerp uitgebracht Voorloopig Verslag van 25 Februari 1936, (Handelingen Koloniale Staten 1935-1936; Bijlagen 26.1.).

In dat Verslag is mede teruggekomen op het verband, dat de Staten legden tusschen de eventueele goedkeuring van een verbod van buitenlandsche loterijen en de wenschelijkheid der totstandkoming eener volksloterij. Zulks naar aanleiding van de, in weerwil van zijn vroegere gedragslijn, door het Bestuur thans bij herhaling gedane mededeeling dat het verband niet (meer) werd gezien. Dit kan op een misverstand berusten. Het schijnt dat de Gouverneur en eventueel zij, die aan de zijde van Zijne Excellentie staan, steeds zochten naar een natuurlijk verband, dat inderdaad niet bestaat. Wèl wordt door het woord „Loterijen” een begripsgemeenschap aangegeven, doch ook hierop wordt niet gedoeld.

Het meer-besproken verband is het verband, dat in groote meerderheid door de leden der Staten tusschen de twee desiderata 
was gelegd, en niet meer is dan een zakelijk verband. Dat de Statenleden bevoegd zijn zulk een verband te leggen staat onzes inziens buiten elken redelijken twijfel. $\mathrm{Zij}$ betreden daardoor gansch niet het terrein, waarop de Uitvoerende Macht de heerschappij heeft te voeren. $\mathrm{Zij}$ streven slechts naar het treffen van een noodig geachten maatregel of voorziening, waarvan de uitvoering behoort tot het gebied van het Bestuur.

Op het Voorloopig Verslag der Staten van 25 Februari 1936 is gevolgd eene Memorie van Antwoord van den Gouverneur dd. 24 Juli 1936, naar aanleiding waarvan een Eindverslag en een Nota verschenen, respectievelijk gedagteekend 28 Juli 1937 en 18 October 1937.

Blijkens de tusschen Bestuur en Koloniale Staten gewisselde stukken had het College aan den Gouverneur het voorstel gedaan de voorwaarden vast te stellen, waaronder eventueel aan buitenlandsche loterijen vergunning zou kunnen worden verleend om deelnemers in de Kolonie te verwerven.

Daarop antwoordde de Gouverneur:

„Het is juist de bedoeling van het Bestuur de buitenlandsche „loterijen te weren en den verkoop van loten dier loterijen in Su„riname tegen te gaan. Daargelaten alleen reeds het feit, dat er in „het algemeen meer geld, aan de loten besteed, de Kolonie ver"laat, dan er geld aan prijzen binnenkomt, is de contrôle uiterma„te moeilijk of een buitenlandsche loterij volgens de daar bestaan„de wettelijke voorschriften is toegestaan".

Zóó moeilijk, als zij is voorgesteld lijkt de hierbedoelde contrôle echter niet. Waarom zouden de bureaux van onze ambassadeurs gezanten en consuls, gevestigd in onderscheidene vreemde, met Nederland bevriende, mogendheden in de onderwerpelijke aangelegenheid geen afdoend juiste inlichtingen kunnen verstrekken? En zouden die informatiën ook niet zijn in te winnen uit het eigen Moederland of uit een der andere Nederlandsche gebiedsdeelen? B.v. over de loterijen „Haco" en „Lotisico”, waaraan hier ongeveer 1 jaar reeds sterk wordt deelgenomen of over de Nederlandsche instelling "de Joodsche Invalide", reeds genoemd in het Voorloopig Verslag van 25 Februari 1936.

De beweerde groote moeilijkheid schijnt niet vol te houden, tenzij moet worden aangenomen, dat het hapert aan de internationale verhoudingen van Nederland. Dit laatste is, gelukkig, niet het geval, gelijk in de Troonrede geregeld wordt medegedeeld.

Meer dan de door het Bestuur gewenschte contrôle is het van belang te achten, te kunnen nagaan of een buitenlandsche loterij 
volgens de in Suriname geldende voorschriften eene vergunning zou kunnen verkrijgen om loten te verkoopen. Daartoe is het noodig, dat algemeene voorwaarden worden vastgesteld, waarbij een vergunningsrecht is te bedingen.

De Stephan's loterij wierp het gouvernement jaarlijks \pm $f$ 50.000.- in den schoot. Voor het verlies van dit bedrag is nog geen equivalent gevonden. Het belang van 's Lands kas vraagt, dat aan dit laatste aandacht wordt geschonken. Er bestaat hier een goede gelegenheid om voor Suriname's berooide algemeene kas, waarop, als bij verrassing, soms zware aanvallen worden gedaan, eenig voordeel te behalen. Reeds veel te lang wordt van die gelegenheid geen voordeel genoten en nu wil het Bestuur die thans geheel doen voorbijgaan.

Met het andere bezwaar tegen buitenlandsche loterijen, dat meer geld, aan loten besteed, de Kolonie zou verlaten, dan er geld aan prijzen zou binnenkomen, kan in het algemeen worden medegegaan, al valt daarbij niet te wijzen op eenig resultaat van een terzake ingesteld onderzoek, eenvoudig, omdat, voor zooveel bekend, een dusdanig onderzoek hier niet plaats vond.

Er mag evenwel aan worden herinnerd, dat tal van Surinamers en velen der uit het buitenland hierheen getrokkenen, die hier een vermogen bijeenbrachten, met de buitenlandsche loterijen hetzelfde euvel gemeen hebben. Véélzeggend is daarom het bezwaar niet.

Aan den anderen kant worde niet vergeten de invloed, dien men moet aannemen, dat mede van de deelneming aan buitenlandsche loterijen uitgaat op de vermindering van het Piauwspel.

Een andere grond, waarop het voorstel van het Bestuur steunt, bestaat in het concordantie-beginsel, neergelegd in de Surinaamsche Staatsregeling (G.B. 1936 No. 156).

Voortdurend wordt bij het maken van wettelijke regelingen, die voor Suriname moeten gelden, van Bestuurszijde de bewering vernomen, dat het noodzakelijk is de overeenkomstige Nederlandsche, dikwijls ook Nederlandsch-Indische, bepalingen over te schrijven. Eenige overtuiging voor die noodzakelijkheid wordt echter zelden geschonken. Naar de hier opgedane ervaringen kan evenwel de gewenschte overeenstemming niet steeds worden aanbevolen. Terecht bepaalt de Staatsregeling dan ook, dat de navolging slechts zooveel mogelijk zij. De wetgever begreep, dat het niet zou aangaan zich blind te staren aan wat elders bestaat met voorbijziening van eigen nooden en behoeften.

Overigens valt op te merken, dat loterijen niet vallen onder 
de onderwerpen, vermeld in art. 120 der Sur. Staatsregeling, waarin het concordantie-beginsel is opgenomen.

Uit de medegedeelde feiten en gemaakte opmerkingen zijn de volgende conclusies te trekken.

De onderwerpelijke aangelegenheid heeft zoowel een moreele als een sociale en economische zijde.

Wordt de zaak aan alle kanten bekeken, dan ontwaart men:

$1^{\circ}$. Dat het in het belang van de gestadige vermindering en algeheele verdwijning van het piauwspel in Suriname en ter wegneming van den lust tot deelneming aan buitenlandsche loterijen, alleszins wenschelijk is gebleven eene permanente volksloterij te zien tot standkomen onder Gouvernementstoezicht.

$2^{\circ}$. Dat er mitsdien voor de Staten hoegenaamd geen reden bestaat terug te komen van hun ten deze ingenomen standpunt.

$3^{\circ}$. Dat het in het belang van 's Lands kas moet worden geacht de buitenlandsche loterijen niet, zonder meer, al dadelijk stop te zetten, doch onder de voorwaarden voor hare toelating de betaling te bedingen van een redelijk vergunningsrecht.

De Staten hebben hierover nog niet beslist. In verband met een door den gedelegeerde van den Gouverneur, den wnd. ProcureurGeneraal Mr. Lambers te kennen gegeven wensch om met zijn lastgever terzake alsnog in overleg te treden, is de verdere behandeling van het ontwerp aangehouden.

Het is te hopen dat Gouverneur Kielstra een willig oor zal verleenen aan de sub. 1 en 3 vermelde desiderata.

Het verloop der zaak hoop ik later mee te deelen.

Paramaribo, 30 November 1937. 